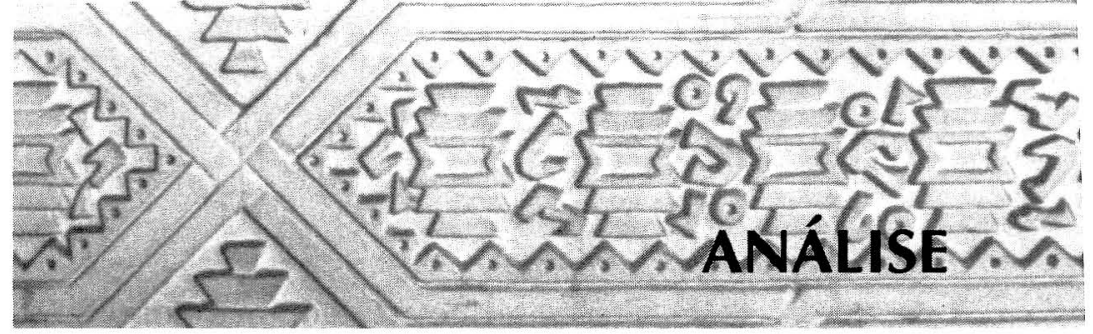

\title{
OS OBJETOS TÊM HISTÓRIA? \\ ENCONTRO DE PASTEUR COM WHITEHEAD \\ NUM BANHO DE ÁCIDO LÁCTICO*
}

\author{
DO OBJECTS HAVE HISTORY? \\ A MEETING BETWEEN PASTEUR AND WHITEHEAD \\ IN A LACTIC-ACID BATH*
}

Bruno Latour**

LATOUR, B.: 'Do objects have history? A meeting between Pasteur and Whitehead in a lactic acid bath'.

História, Ciências, Sauide - Manguinbos, II (1), 7-26 Mar.-Jun. 1995.

Did Pasteur discover, construct, invent lactic acid? This Gordian knot in social studies of the sciences is bappily cut when the scene played out at Lille in 1857 is peopled with Whiteheadean conceptual characters. The Nature addressed by Pasteur does not speak the language of scientific utterances but neither is it mute; it is imbued with propositions. Insofar as Pasteur plays the character of a scientist, be is 'acted on' by a singular proposition - "a tale that perhaps might be told," as Whitehead would say, but that will only be true or false if Pasteur manages to make a real world correspond to this proposition, a world capable of providing logical subjects, and thus offering proof to "whomever judges with impartiality." A bybrid-mediator-translator of Pasteurian and microorganismic propositions, the experimental environment "makes the event," in an encounter from which a new Pasteur and a new yeast emerge, partners of a new bistory.

KEYWORDS: Pasteur, Whitebead, lactic acid, bistoricity.

\begin{abstract}
"But in the real world it is more important that a proposition be interesting than it be true. The importance of truth is, that it adds to interest."

"It must be remembered that the phrase 'actual world' is like 'yesterday' and 'tomorrow', in that it alters its meaning according to standpoint."
\end{abstract}

Process and Reality

* Artigo publicado originalmente em L'effet Whitehead, Vrin, 1994.

** Centre de Sociologie de la Innovation, École des Mines, Paris.
Este artigo quer fazer reagir, no sentido químico do verbo, a filosofia de Whitehead a respeito de "personagens conceptuais" inusitados ou mesmo incongruentes. De minha parte, quero saber que luzes a metafísica de Whitehead poderia lançar sobre uma questão candente na história social das ciências, a historicidade das 
1 A apresentação canônica de tal princípio está em H. Collins, 1985.

2 Os exemplos mais elaborados encontram-se em S. Shapin e S. Schaffer, 1993; e em C. Licoppe, 1994. coisas, que até agora não recebeu solução satisfatória. Como bom filósofo empírico, vou partir de um exemplo, a descoberta-invenção-construção do fermento do ácido láctico por Pasteur em 1857.

Pretendo, neste artigo, montar uma prova dupla: de que maneira Whitehead nos permite recolocar uma grande questão da filosofia da história? E como se comporta sua filosofia quando tem de enfrentar os detalhes concretos de uma situação experimental?

\section{Alguns debates recentes no estudo das ciências}

Antes de mergulhar Whitehead num banho de ácido láctico, convém resumir para o leitor os episódios precedentes.

"The simple notion of an enduring substance sustaining persistent qualities, either essentially or accidentally, expresses a useful abstract for many purposes of life. But whenever we try to use it as a fundamental statement of the nature of things, it proves itself mistaken. It arose from a mistake and has never suceeded in any of its applications" (Whitehead, 1978).

Por razões bem diferentes esta crítica ao substancialismo, tão importante para Whitehead, poderia ser partilhada por muitos historiadores da ciência. Segundo eles, num relato de descoberta não se deve apelar para qualquer substância exterior ao trabalho humano, a fim de explicar-lhe a gênese. ${ }^{1}$ É certo que, como Kant, para evitar os malfeitos do idealismo, a maior parte dos novos historiadores não lhe negam existência, mas o que eles querem é fazer emergir os atributos concretos apenas de um lado, o do espírito que conhece, ou, mais recentemente, o da prática do grupo dos cientistas que manipulam e verificam no recinto fechado e local do laboratório. ${ }^{2}$ Para criticar o substancialismo devemos simplesmente, na história de uma descoberta, abster-nos de conferir qualquer papel aos seres não-humanos e construir o relato apenas com a ajuda das práticas, dos lugares, dos instrumentos, das autoridades, das instituições e dos acontecimentos históricos fornecidos pelo contexto. Com isso, espera-se que uma multidão de pequenas determinações acrescentadas umas às outras acabe por contar tanto quanto a substância sempre-já-ali dos relatos de descobertas 'à moda antiga'. Como mostrou Isabelle Stengers em um livro recente (1993), existe em tal abordagem alguma coisa de inverossímil para o cientista praticante, alguma coisa de irrealista, não apenas no sentido filosófico do termo, mas também no sentido corrente de improvável. Falta aí algo de essencial. Será que falta justamente a essência? Não, 
3 A apresentação canônica está em D. Bloor, 1982. Para uma justificativa recente, ver o prefácio da segunda edição (D. Bloor, 1991).

4 G. Canguilhem, 1968, apresenta sua forma mais extrema.

5 Esta conclamação se encontra até no último parágrafo do livro, mesmo assim sofisticado, de S. Shapin e S. Schaffer, op. cit. e o interesse de Whitehead é imaginar um realismo sem substância, um realismo histórico radical: "The Castle Rock of Edinburgh exists from moment to moment, and from century to century, by reason of the decision effected by its own historic route of antecedent occasions" (Whitehead, 1978, p. 43).

Para escapar à história social das ciências, ao construtivismo social e aos diferentes avatares do kantismo, foi preciso passar de um princípio de simetria restrita a um princípio de simetria generalizada. O primeiro princípio pedia aos historiadores que julgassem os relatos de descoberta com justiça, tratando no mesmo pé os cientistas que estavam errados e os que tinham razão. ${ }^{3}$ Este princípio, diametralmente oposto à tradição epistemológica francesa, que exigiria, ao contrário, distinguir a "ciência vencida" da "ciência sancionada", permitiu belos efeitos de contextualização histórica. As vitórias de Boyles sobre Hobbes, de Newton sobre o cartesianismo ou de Pasteur sobre Pouchet não diferem daquelas, provisórias, de Napoleão sobre o imperador Alexandre, ou de Pompidou sobre Poher. A história das ciências deixa de se distinguir da história pura e simples, "cheia de som e de fúria".

O preço a pagar por tal reunificação da história com a história das ciências continua, no entanto, muito alto. O princípio de simetria restrita só consegue igualar as oportunidades dos vencedores e dos vencidos (anteriormente dos racionais e dos irracionais), proibindo aos dois protagonistas o acesso aos próprios fenômenos que, no entanto, eles consideram sua única razão de ser. Parafraseando Whitehead a respeito de Hume, há algo de heróico nesta abstenção. $\mathrm{Na}$ arbitragem entre vencedores e vencidos, o historiador partidário da simetria teria de se abster de tocar até mesmo nas coisas que proliferam nas mãos e nos corpos de todo o mundo. A natureza, dizem eles com uma ascese de ioga, não intervém nas interpretações que fazemos a seu propósito. ${ }^{5}$

Compreende-se a razão de tal determinação. Os historiadores partidários da simetria reagem contra os abusos dos substancialistas que se contentam em julgar os vencedores da história das ciências explicando, na maior candura, que eles ganharam porque eram mais racionais ou porque tiveram mais acesso à natureza das coisas. Insistindo, pela primeira vez, nas dificuldades da experiência, nas incertezas dos instrumentos, na localização irremediável das práticas, na ambigüidade das interpretações, na importância da comunidade de colegas mais ou menos dignos de crédito, os historiadores construtivistas podem facilmente ridicularizar - como seu ancestral Hume fez com a percepção os que acreditam se beneficiar com um acesso imediato ao real e que tomam pela essência permanente das coisas certos hábitos sociais ou cognitivos surgidos ontem. 
6 Ver as exposições canônicas em B. Latour, 1984 , a e 1984 , b segunda parte; M. Callon, 1986, pp. 169-208; e B. Latour, 1989.

7 Para uma apresentação da filosofia desta teoria dos atores-redes, ver $B$. Latour, 1991.
O princípio de simetria generalizada evita que se chegue à anorexia nesta heróica ascese. ${ }^{6}$ Não se trata mais, dessa vez, de igualar as oportunidades de vencedores e vencidos, proibindo igualmente aos dois grupos o acesso ao real, mas de deixar todos os grupos construírem simultânea e simetricamente sua realidade natural e sua realidade social. Como iogas privados de alimento por demasiado tempo e obrigados a dormir em camas de pregos por demasiadas noites, permite-se enfim aos descobridores fartar-se de realidade e dormir em colchões de pluma! Basta este pequeno empurrão para sair do kantismo, já que, para explicar uma descoberta, não se deve mais escolher entre o acesso privilegiado ao real e a determinação por milhares de pequenas causas sociais ou práticas. Percebe-se, com efeito, que a definição do real como reserva ou âncora contra o idealismo só tinha sentido em contraste com o espírito conhecedor (ou o laboratório, ou o paradigma). A revolução copernicana, contra-revolução copernicana e meia. O descobridor estabelece, ao mesmo tempo, o que ele é, o mundo em que se situa, e as numerosas causalidades sociais, práticas e históricas compatíveis com o tipo de fenômenos com que ele povoa o coletivo. Atenua-se a diferença entre questões ontológicas, epistemológicas e sociológicas. A questão se torna: em que mundo sócio-natural aceitamos viver? O princípio de simetria generalizada não apaga o princípio de simetria restrita, mas estende-o à questão da natureza e à da sociedade, fazendo aparecer um novo objeto: o coletivo de humanos e de não-humanos. ${ }^{7}$

Esta solução, no entanto, não tem a metafísica de suas ambições. Embora tenha deixado de ser antropomórfica, continua tão frágil quanto o sentido dado à palavra coletivo. Se por este nome designamos a atividade demiúrgica de pesquisadores capazes de engendrar não apenas a natureza, como ainda a sociedade e a história nas quais eles se situam, aproximamo-nos perigosamente dos grandes relatos do idealismo absoluto que, também eles, acreditavam ir além de Kant. Caso se trate de uma proliferação semiótica que dote de certas propriedades os humanos, os nãohumanos, os objetos circulantes, as posições enunciativas e o contexto inscrito no texto, mergulhamos então no discurso, em campos de posições sem sujeitos e afastamo-nos ainda mais do realismo que buscávamos. A "morte do homem" sucede brutalmente ao "super-homem". Caso se trate de deixar os não-humanos multiplicarem-se tanto na sociedade como nos sujeitos, corremos o risco de naturalizar o conjunto da história e dos relatos sem mais poder dotar os objetos de sua incerteza, de sua transcendência, de seu "tremor". Passamos a uma vontade de potência 
que ancoraria brutalmente o discurso e as ações na biologia ou na física.

Para ter a certeza de escapar a estes três perigos - enquadramento na sociedade, enquadramento na linguagem, enquadramento na natureza -, é preciso sair da ambigüidade da palavra coletivo, até mesmo abandonar todo "coleto-centrismo" bem como as noções de autor, de ação, de sujeitos, de objetos, de humanos e de não-humanos, que serviram provisoriamente para escapar ao kantismo. É preciso assim, como Whitehead, ousar comerciar com a metafísica, a despeito do embargo pronunciado contra ela tanto pela filosofia analítica como pelo construtivismo, seja ele social ou simétrico.

Chegados a esse ponto, depois de ter resumido os episódios precedentes, é preciso, no entanto, mudar de maneira e acompanhar um caso concreto, a fim de não perder o fio deste realismo histórico sem substância intemporal que Whitehead nos permite imaginar.

8 Umá análise semiótica do artigo se encontra em I3. Latour, 1993, pp. 127 42. Para uma apresentação geral do pastorianismo, a melhor fonte continua sendo G. Geison, 1974 , pp. 351-415. Aqui utilizo apenas o texto, para dele extrair suas ontologias variáveis sem me preocupar com outros arquivos ou traços que me vinculariam com mais segurança ao laboratório ou à prática de Pasteur.

9 Para uma apresentação dos químicos e de suas ideologias profissionais, ver B. Bensaude-Vincent c I. Stengers, 1992.

\section{Relato de uma descoberta de Pasteur}

Em 1858, pouco tempo depois de ter 'posto em evidência' o fermento do levedo de cerveja, Pasteur relata, num célebre memorial para a Académie des Sciences, a descoberta de um fermento próprio ao ácido láctico. ${ }^{8}$

Para historicizar esta descoberta, precisamos apenas de uma forma muito elementar de enquadramento histórico. Hoje, a fermentação láctica não é mais objeto de discussão e pode-se encomendar, por catálogo, diversas variedades e quantidades de fermento para as leiterias e queijarias de todo o planeta. Mas basta se 'remeter às condições da época' para avaliar toda a originalidade desta memória, e, portanto, a parte que Pasteur pode reivindicar para si próprio. Em meados do século XIX, nos meios científicos marcados pela química de Liebig, a presença de um microrganismo específico para explicar as fermentações significava um retrocesso, já que foi se livrando das obscuras explicações vitalistas que a química tinha acabado de conquistar o direito de reivindicar o status de ciência.? Segundo ela, a fermentação poderia ser explicada de maneira puramente química pela degradação das matérias inertes, sem intervenção de qualquer ser vivo. De qualquer forma, os especialistas em fermentação nunca tinham visto microrganismos associados duravelmente à transformação do açúcar.

"Pesquisas minuciosas não conseguiram até agora revelar o desenvolvimento de seres organizados. Os observadores que os reconhe- 
10 São surpreendentes as ressonâncias entre este admirável livro sobre filosofia chinesa de F. Jullien, 1992, e A. N. Whitehead, op. cit. ceram estabeleceram, ao mesmo tempo, que eles eram acidentais $e$ perturbavam o fenômeno. Os fatos, assim, pareciam muito favoráveis às idéias de Liebig ou às de Berzelius. Aos olhos do primeiro, o fermento é uma substância excessivamente alterável que se decompõe e que estimula a fermentação após a alteração que ela própria sofre, abalando por comunicação e desorganizando o grupo molecular da matéria fermentescível. Aí está, segundo Liebig, a causa primeira de todas as fermentações e a origem da maior parte das doenças contagiosas. Para Berzelius, o ato químico da fermentação entra nas ações de contato. Tais opiniões obtêm a cada dia um novo crédito ... . Estes trabalhos estão de acordo em rejeitar a idéia de uma influência qualquer da organização e da vida na causa dos fenômenos que nos ocupam" (grifos meus).

E Pasteur acrescenta: "Sou levado a uma maneira de ver inteiramente diferente." O descobridor vai parecer ainda mais ativo por ter todo o mundo contra si, tanto a opinião unânime dos químicos como as pesquisas minuciosas dos especialistas. $\mathrm{O}$ descobridor não ergue o véu onde se ocultava desde sempre o fermento da fermentação láctica. Ele age. Acontecimento da história, ele reverte uma situação que lhe era de todo adversa: da mesma maneira, um historiador poderia acompanhar o obscuro general De Gaulle desde junho de 1940, em Londres, até seu triunfo, cinco anos mais tarde, nos Champs-Elysées. A ação de Pasteur não consiste mais, porém, em impor obrigatoriamente um quadro ou uma visão a uma fermentação — se bem que, como veremos, mais tarde ele formula o problema nestes termos. Ele afirma, na verdade, que "foi levado a uma maneira de ver". Sua atividade consiste propriamente em se deixar levar pela "propensão das coisas", para retomar a bela expressão de François Jullien. ${ }^{10}$ Mesmo quando age para fazer emergir o fermento contra a opinião do mundo, ainda assim se deixa levar pelas coisas, mesclando de outra maneira a sorte de um sujeito - autor digno de crédito que reivindica a polêmica e a ação - e de um objeto - que leva o sujeito a modificar sua visão.

$\mathrm{Na}$ história política e militar existem recursos que permitem pesar o papel respectivo da ocasião, das circunstâncias, do gênio próprio, da sorte, e, enfim, da atribuição da responsabilidade a alguns operadores reconhecidos como chefes ou demiurgos. Quando se trata de colocar no relato os seres que se descobriu, o historiador das ciências se faz mais tímido, mais hesitante. Por maior que seja a heterogeneidade dos fatores que a história usa, ela nunca parece tão grande como na história das ciências, onde é preciso integrar a curta existência de Pasteur, a duração mais longa da química ou do Segundo Império, aquela ainda mais longa das fermentações alcoólicas e lácticas que remontam ao 
11 Ver o artigo seminal de F. Jacq, 1993.

12 Pode-se encontrar em S. Schaffer, 1991, pp. 174-92; e em H. Collins e S. Yearley, 1992, pp. 301-26, duas críticas muito severas ao princípio de simetria generalizada. Para uma resposta na lógica dos atores-redes que o presente artigo pretende melhorar, ver $M$. Callon e $B$. Latour, op. cit., pp. 343-68. neolítico e aquela, infinitamente mais longa, absolutamente mais longa, do fermento do ácido láctico sempre já presente. Dito de outra forma, comparado ao historiador puro e simples, o historiador das ciências aborda um monstro a mais: uma vez descoberto por Pasteur em 1857, o fermento do ácido láctico sempre esteve lá, tanto no neolítico, nas cabaças do Homo sapiens, como hoje em dia, responsável pelo soro que se torna azedo em todas as leiterias do planeta. Como fazer para historicizar a criação de um ser que parece logo transbordar de seu quadro histórico para retornar na totalidade do tempo e se espalhar na totalidade do espaço?

A única solução, comum na história, consiste em atribuir historicidade a todos os elementos que entram no relato. ${ }^{11}$ De Gaulle se transforma, mas também Churchill, a Alemanha, os radares, as opiniões públicas, os submarinos, o cálculo dos comboios perdidos, a dívida respectiva dos bancos centrais, e assim por diante, segundo escalas e ritmos diferentes. Sempre existe, portanto, de maneira mais ou menos igual, reciprocidade na aventura, no acontecimento. De Gaulle modifica Churchill que, por sua vez, o transforma. É justamente esta reciprocidade que parece impossível na história das ciências, pois seria preciso partilhar o acontecimento entre Pasteur e o ácido láctico! No entanto, a simetria generalizada exige esta partilha. Não apenas o fermento 'chega a' Pasteur - transformando este honrado químico provinciano em um mestre da microbiologia mundial -, como Pasteur 'chega ao' fermento do ácido láctico - transformando esta fermentação por contato na cultura de um fermento que se alimenta de açúcar. Sim, é preciso admitir, o jovem Louis Pasteur de Lille deve ser contado como um episódio no destino, na essência, na trajetória do fermento láctico. É fácil conceber o absurdo de tal posição e o escândalo que deve ter suscitado, ${ }^{12}$ sobretudo se, em lugar do fermento, ainda próximo dos organismos mergulhados na história agitada dos vivos, o argumento for aplicado à gravidade ou à cosmologia. Newton chegaria à gravitação universal? O CERN surgiria como conseqüência do Big Bang?

Se, buscando outra vez refúgio no confortável quadro kantiano, se falasse apenas de representação, o caso com certeza não apresentaria qualquer dificuldade. Pasteur transforma as idéias que os químicos e os fabricantes de laticínios têm sobre a fermentação láctica, assim como Newton modifica nossas idéias sobre a ação à distância dos corpos celestes. Seria mais fácil voltar à história já que se ficaria entre homens, com suas representações, suas visões do mundo, seus interesses mais ou menos apaixonados. A história das ciências - social ou intelectual - poderia se apresentar com uma audácia ainda maior já que se limitaria apenas às representações, deixando fora de alcance os fenômenos propriamente ditos. Mas, com a simetria generalizada, queremos alcançar os 
13 Trata-se, na verdade, de dar uma ontologia à frase de Kuhn, que encerra para seu autor um sentido psicossocial: "Se bem que o mundo não mude depois de uma mudança de paradigma", escreve ele, "o bomem de ciência trabalba dai para a frente num mundo diferente. Nem por isso deixo de estar convencido de que devemos aprender a encontrar um sentido para esta afirmação. ... Não é possível reduzir o que se passal durante uma revolução científica a uma reinterpretação de clados estáveis e independentes", T. Kuhn, 1983, p. 171.

14 Tomo emprestado estes termos do excelente artigo de J. B. Cobb, 1993. fenômenos, sair da casa da infância do idealismo e encontrar, com o realismo, os riscos da ontologia, sem perder as incertezas da história nem a localização das práticas. ${ }^{13}$ Assim, é preciso explorar este caminho, por mais bizarro que possa parecer, e falar de Pasteur como um acontecimento que se dá com o ácido láctico. O que parecia absurdo numa metafísica da essência e dos atributos pode se tornar um jogo de crianças para uma ontologia dos acontecimentos e das relações. ${ }^{14}$

\section{Algumas ontologias de geometria variável}

Utilizando o vocabulário de Whitehead, o laboratório de Pasteur parece-nos uma ocasião aberta a trajetórias de entidades que herdam circunstâncias precedentes ao 'decidir' perseverar, de uma nova maneira, no ser.

Certas entidades vão percorrer o laboratório como práticas estabilizadas. É o caso do próprio ácido láctico:

"O ácido láctico foi descoberto por Scheele, em 1780, no soro azedo. Seu procedimento para retirá-lo de tal matéria ainda hoje em dia é o melhor que se pode seguir. Ele inicialmente reduziu o soro a um oitavo, por evaporação. Filtrouto, saturou-o de cal para precipitar o fosfato de cálcio. O licor foi filtrado e dissolvido em três vezes seu peso em água; derramou nele, gota a agota, o ácido oxálico para precipitar toda a cal. Evaporou o licor até a consistência do mel ..." (grifos meus).

O ácido não se apresenta como uma substância durável no tempo e definida por seus atributos, mas por um conjunto de verbos que remetem a gestos de laboratório. Reduz-se a um procedimento e não tem outra definição que não a de ser coextensivo ao conjunto de tais manobras. Pouco importa que a lista de operações seja longa, já que cada uma delas faz parte da rotina de um laboratório de química bem equipado. O encaixe entre os subprogramas de ação não fragiliza a essência, na medida em que químicos hábeis compreendem, sem esforço, o significado de gestos como filtrar, evaporar, precipitar, e na medida em que tomem seu agenciamento como uma só e única caixa-preta.

Não ocorre o mesmo com o fermento, de que toda a comunidade científica duvida em 1857:

"Quando se examina com atenção uma fermentação láctica ordinária, há casos em que se pode reconbecer em cima do depósito de cálcio e de matéria azotada manchas de uma substância cinzenta que algumas vezes formam certas zonas na superfície do depósito. Esta matéria é levada pelo movimento gasoso. Seu exame ao 
microscópio não permite, quando não se está prevenido, distinguila do caseum, do glúten desagregados etc.; de tal maneira que nada indica que se trate de uma matéria especial, nem que tenha nascido durante a fermentação. Seu peso aparente é sempre muito pequeno, comparado ao da matéria azotada primitivamente necessária para a realização do fenômeno. Enfim, muitas vezes ela está de tal forma misturada à massa de caseum e de cálcio, que em cuja existência não se poderia crer. É ela, que desempenba, não obstante, o papel principal" (grifos meus).

Contrariamente ao ácido láctico, a própria existência do fermento está em questão. Não existem mais gestos rotinizados que permitam garantir-lhe a presença regular. A própria entidade define-se apenas por um "serviço mínimo" que aparece como "manchas de uma substância cinzenta que algumas vezes formam certas zonas na superfície do depósito". Não é possível existência mais ínfima! O contraste surge ainda mais forte com a frase em forma de desafio que conclui o parágrafo. Contra Liebig e Berzelius, como acabamos de ver, Pasteur foi "levado a uma maneira de ver inteiramente diferente". Tal conduta e tal retorno dependem desta nova conversão pela qual um ser "em cuja existência não se poderia crer ... desempenha, não obstante, o papel principal"!

É fácil imaginar que os termos "sujeito" e "objeto" passam a ser de pouca utilidade para acompanhar como o fermento, criticado por todos, invisível, pobre mancha ao fundo de um recipiente de vidro, logo se transforma no "único responsável" pela fermentação láctica. Pasteur aposta alto neste negócio, assim como o fermento, Liebig e os produtores de laticínios. Não observamos um homem dotado de faculdades a descobrir um ser definido por seus atributos. O que vemos é um corpo com membros múltiplos e parciais buscando fazer advir em seu laboratório, por uma série de provas, uma seqüência regular de ações:

"Vou, de início, indicar o meio de isolar [esta matéria especial], de prepará-la em estado de pureza. Extraio do levedo de cerveja sua parte solúvel, mantendo-a por algum tempo à temperatura da água fervente com quinze a vinte vezes seu peso em água. O licor, solução complexa de matéria albuminóide e mineral, é filtrado com cuidado. Faz-se dissolver cerca de 50 a 100 gramas de açúcar por litro, acrescenta-se o cálcio e semeia-se um pouco desta matéria cinzenta de que já falei, extraída de uma boa fermentação láctica comum; depois se leva à estufa a $30^{\circ}$ ou $35^{\circ}$. Também é bom fazer passar uma corrente de ácido carbônico para expulsar o ar do frasco, ao qual se adapta um tubo recurvo que mergulha n'água. Já no dia seguinte uma fermentação viva e regular se manifesta" (grifos meus). 
15 O erro de Schaffer, em S. Schaffer, op. cit., é atribuir a interpretive flexibility apenas aos pesquisadores "às voltas" com os dados. Introduzir os nãohumanos significaria sempre, segundo ele, fazer calar as controvérsias. Inversamente, I. Hacking, 1992, pp. 180-237, não tem qualquer dificuldade em dar uma interpretação construtivista dos fatos sociais, já que foi entendido, de uma vez por todas, que eles não podem corresponder a nada que não seja o arbitrário das profecias auto-realizadoras.
No laboratório, o corpo cuidadoso e hábil de Pasteur serve de ocasião, de circunstância, de concrescência ao estabelecimento durável de uma fermentação láctica. Através de certos gestos (filtrar, dissolver, acrescentar), ingredientes (levedo de cerveja, licor, cálcio), aparelhos (torneiras, recipientes, estufas, tubos), instrumentos de medida (termômetros, balanças, termostatos), pequenos truques do ofício (é bom), a fermentação se torna visível e estável. Neste estágio de variação, a essência da fermentação nada mais é do que esta exibição em tais circunstâncias práticas e locais.

O enquadramento histórico, dessa vez, ultrapassa o simples "retorno às incertezas da época". Não se trata mais apenas de encontrar Pasteur trêmulo em seu laboratório, diante da idéia de perder não apenas sua fermentação como também o fermento incerto que lhe parece "correlativo da vida". É a fermentação láctica que treme, ela também. Tal manifestação "viva e regular", controlada, jamais the aconteceu em lugar algum, desde que o mundo é mundo. O pequeno laboratório do decano da Faculdade de Ciências de Lille constitui um entroncamento decisivo na trajetória desta fermentação, já que ali ela se torna justamente visível e pura. Não é mais apenas Pasteur quem muda sua 'representação' da fermentação, mas é ele próprio, em seu ser, em sua história, em suas ascendências e descendências que modifica suas manifestações. Se Pasteur hesita, a fermentação hesita, ela também.

A ambivalência, a ambigüidade, a incerteza, a plasticidade não vêm perturbar apenas os humanos que avançam, tateando, na direção de fenômenos garantidos em si mesmos. ${ }^{15}$ Elas acompanham também os seres aos quais o laboratório oferece uma nova possibilidade de existência, uma oportunidade histórica. Sem Pasteur, sem a filtração, sem o tubo recurvo, sem o ato de semear num meio de cultura, a fermentação jamais seria 'manifesta'. Ela conheceu outras existências antes de 1857, alhures, mas sua nova concrescência na Faculdade de Ciências de Lille, entre as mãos de um químico ambicioso novo em folha, oferece-lhe uma nova existência, única, datada, localizada, feita em parte de Pasteur ele mesmo transformado por sua segunda grande descoberta e do laboratório - ele mesmo corpo e espírito de Pasteur, inteligência distribuída, teoria materializada nos instrumentos, assembléia muda e materializada de toda a química havia cem anos. Estamos fazendo a história de Pasteur e de seu fermento, do fermento e de seu Pasteur; estamos falando de acontecimentos definidos apenas por suas relações. 
16 Para acompanhar esta história natural dos seres envolvidos nas redes científicas, ver B. Latour, 1989.

\section{Do acontecimento à substância}

Qualificando assim a história comum de um pesquisador, de uma disciplina, de um laboratório, de uma montagem, de um fermento e de uma teoria, não perdemos com isso a substância e seus atributos, mas o sentido da palavra substância vai mudar profundamente e se torna a atribuição progressiva de propriedades estáveis atreladas por uma instituição a um nome ligado duravelmente a uma prática, circulando o todo numa rede relativamente padronizada. ${ }^{16}$ Tal transição do acontecimento à substância definida de maneira nova coloca um sério problema de descrição e de interpretação, de que Pasteur se safa com duas aparentes contradições.

No início de seu memorial, o autor ainda não sabe que propriedades atribuir a que essências. No final, o fermento possui a mesma solidez, recentemente descoberta, da cerveja. A substância dotada de atributos oferece um caso particular do acontecimento definido por suas relações, uma certa maneira de resumir, de rotinizar, de estabilizar, de institucionalizar os acontecimentos. Tudo se passa como se os atributos precedessem a uma essência. Tome-se esta passagem, raramente estudada, entre dois parágrafos do memorial:

"Vejamos agora quais são as características de tal substância, cuja produção é correlativa dos fenômenos compreendidos sob a denominação de fermentação láctica. Tomada em massa, ela se assemelha completamente ao levedo comum escoado ou prensado. É um pouco viscosa, de cor cinzenta. Ao microscópio, ela é formada por pequenos glóbulos ou de artigos muito curtos, isolados ou em grupo, constituindo flocos irregulares semelhantes aos de certos precipitados amorfos ... . Ela pode ser recolbida e transportada para longe sem perder sua energia. Sua atividade apenas se enfraquece quando é secada ou quando é fervida na água. Enfim, é preciso muito pouco deste levedo para transformar um peso considerável de açúcar.

Encontramos aí todas as características gerais do levedo de cerveja, e tais substâncias provavelmente têm organizações que, em uma classificação natural, devem ocupar dois gêneros vizinhos ou duas familias próximas" (grifos meus).

No primeiro parágrafo, a essência só se define pelas provas a que se submete um " $x$ ", uma "matéria especial" anônima, de que se registram as respostas recentemente tornadas estáveis graças aos cuidados e à habilidade do cientista, bem como ao gênio do lugar. Cada prova surpreende ainda por seu frescor: " $x$ " pode ser transportado sem se enfraquecer! É preciso muito pouco dele para modificar um peso considerável de açúcar! Os atributos 
17 Para o estudo detalhado de tais transformações sucessivas no texto de Pasteur, ver B. Latour, 1993. ainda flutuam sem poder se ligar a um substrato. Sente-se ainda no texto as hesitações, os escrúpulos, as tergiversações de Pasteur diante de tal matéria viscosa e cinzenta que resiste à secura ou à fervura. A prova ainda a define em todo seu frescor, como se só se pudesse induzir suas competências a partir de desempenhos perturbadores.

Mas, no parágrafo seguinte, a coalescência aconteceu. A "matéria especial" não mais parece apenas com o levedo de cerveja, não é apenas composta de glóbulos, de flocos irregulares. O fermento, agora nomeado, torna-se uma substância e ocupa uma posição bem visível numa classificação por gênero e espécie. Os atributos que flutuavam ao acaso tornam-se as marcas de uma essência durável, e não apenas de uma rotina estabilizada, como o ácido láctico estudado antes. ${ }^{17}$

Como explicar a passagem de uma longa série de provas hesitantes a um ser resumido por um nome? Por que os atributos acabam por se alojar numa substância, como um vôo de pombos de volta ao pombal?

A resposta dos historiadores inspirados pelo primeiro princípio da simetria não deixa dúvida. Foi preciso que o próprio Pasteur desse um pequeno empurrão, a fim de reunir em um conceito a poeira indeterminada dos fatos. Sem o pressuposto do microrganismo, ele jamais teria conseguido resumir a longa lista de provas em um único fermento, os desempenhos nunca teriam permitido supor uma tal competência de micróbio organizado. $\mathrm{Na}$ verdade, para os historiadores da ciência desde Duhem, sempre foi preciso uma teoria, um preconceito, um pressuposto, um quadro conceitual, um paradigma, a fim de ordenar os dados que jamais se pode encontrar frente a frente. Retorno obrigatório a Kant e a seus epígonos sociólogos. Curiosamente, Pasteur faz-se a mesma pergunta e parece comungar da tese dos construtivistas, antes de se contradizer uma segunda vez:

"Ao longo de todo este memorial, raciocinei na hipótese de que o novo levedo é organizado, que é um ser vivo e que sua ação química sobre o açúcar é correlativa de seu desenvolvimento e de sua organização. Caso me viessem dizer que nestas conclusões eu vou além dos fatos eu responderia que isto é verdade, no sentido de que me coloco francamente numa ordem de idéias que, para falar rigorosamente, não podem ser irrefutavelmente demonstradas. Eis minha maneira de ver. Todas as vezes que um químico se ocupar de tais misteriosos fenômenos, e que tiver a felicidade de lhes fazer dar um passo importante, ele será instintivamente levado a colocar a causa primeira em uma ordem de reações com relação aos resultados gerais de suas próprias pesquisas. É a marcha lógica 
18 Personagem de vários romances policiais populares na França, que tinha intuições geniais, mas que pretendia sempre seguir simplesmente "o longo caminho de sua razão". (N. do T.). do espírito humano em todas as questões controversas" (grifos meus).

$\mathrm{Na}$ mais pura tradição racionalista, Pasteur insiste que uma teoria é obrigatória para que os fatos possam falar e mobiliza no mesmo impulso o instinto, a lógica do espírito humano e as maneiras de ver. Ele sabe, como Rouletabille, ${ }^{18}$ que primeiro é preciso seguir "o longo caminho de sua razão". Mas ele não fica nesta solução do pequeno 'empurrão' que, no entanto, encantaria os construtivistas sociais. Sem medo de se contradizer, passa em seguida ao realismo mais tradicional e afirma tranqüilamente:

"Ora, é minha posição, no ponto em que me encontro de meus conhecimentos sobre o assunto, que quem quer que julgue com imparcialidade os resultados deste trabalho e dos que publicarei em breve, reconbecerá comigo que a fermentação aí se mostra correlativa da vida, da organização dos glóbulos, não da morte ou da putrefação de tais glóbulos, assim como não aparece aí como um fenômeno de contato, onde a transformação do açúcar se realizaria na presença do fermento sem nada lhe dar, sem nada lhe tomar. Estes últimos fatos, como logo se verá, são negados pela experiência" (grifos meus).

Dêem-me colegas imparciais, e eles reconhecerão comigo o que a experiência afirma sem contestação, esta mesma experiência à qual, na citação precedente, era necessário acrescentar alguns pressupostos porque ela não podia demonstrar, sem refutação, a presença de microrganismos. Contradição flagrante! Os historiadores sociais que, por ascese, se obrigam a jamais apelar para a experiência incontestável, para fazer calar as controvérsias, não mais aplaudem o grande homem.

Pasteur, no entanto, passa, num piscar de olhos, de uma epistemologia a outra, assim como o fermento, denominado " $x$ ", passa suavemente do acontecimento à substância. Antes de Whitehead, não tínhamos como escapar de tal dilema. Pareceria que deveríamos sempre escolher entre dois males, como uma gota que um golpe de vento faz passar de um lado a outro de uma linha de divisão das águas. Ou a gota vai juntar-se à vertente da inventividade humana, cuja história é fácil de formular porque ela impõe categorias mais ou menos arbitrárias a uma realidade que jamais se poderá conhecer, ou vai para a outra vertente, a da natureza, a dos objetos sem história sempre já presentes e que os humanos se contentariam em descobrir.

Whitehead abre uma nova possibilidade e nos permite compreender por que a contradição é apenas aparente. O fermento do ácido láctico muda sua história em contato com Pasteur e seu laboratório. Ele é bem real, mas sua realidade histórica o 
coloca em paridade com o pesquisador e o laboratório no qual se mistura. $\mathrm{O}$ ácido láctico também passou por uma mutação. $\mathrm{O}$ fermento recebeu o empurrão que Pasteur lhe deu como uma oportunidade histórica de se manifestar, alterando toda a sua trajetória. O fermento propõe, Pasteur dispõe. Pasteur propõe, o fermento dispõe. Pasteur não impôs seus pontos de vista a uma forma infinitamente plástica, nem descobriu, tateando, a resistência de uma forma infinitamente robusta; ele deu a um fenômeno sua oportunidade. É por isso que, ao escrever o memorial, não vê nenhuma contradição entre as duas últimas citações, que, aos olhos de um epistemólogo ou de um historiador social, em tudo divergem. Uma ontologia, mais contra-intuitiva ainda do que a da história social das ciências, permite imiscuirmo-nos no senso comum de um cientista. Seria preciso compreender esta frase enigmática que ele pronuncia no elogio acadêmico que fez de Littré, cuja cadeira assume:

"O experimentador, homem de conquistas sobre a natureza, se encontra todo o tempo às voltas com fatos que ainda não se manifestaram e só existem, em sua maioria, como potência de devir nas leis naturais. O desconhecido no possível e não no que foi [contrariamente ao historiador Littré], eis o seu domínio ..." (Pasteur, 1939, p. 334, grifos meus).

\section{À prova de Whitehead}

Por que esta solução de uma historicidade das coisas, embora seja forjada com o cunho do bom senso, parece, à primeira vista, tão inverossímil, tão insensata? Por causa de nossas idéias sobre a natureza, sobre a transcendência e sobre a causalidade, idéias cujo peso Whitehead nos permite reduzir ao extremo.

Suponhamos que calculamos os ingredientes que entram na composição do fermento láctico de 1857 , a fim de compreender a co-produção de tal fato científico. Uma vez abandonados os relatos de descoberta à moda antiga, bem como os de construção social, mais recentes, devemos fazer uma lista heterogênea que compreende, entre muitos outros fatores, Pasteur, a Faculdade de Ciências de Lille, Liebig, as queijarias, os equipamentos de laboratório, o levedo de cerveja, o açúcar e, enfim, o fermento. Não há essencialismo nesta lista, já que cada entidade se define apenas por suas relações. Se as relações mudam, a definição muda igualmente: a Faculdade de Ciências com ou sem Pasteur não é exatamente a mesma; o açúcar com ou sem o fermento láctico não é, de modo algum, o mesmo; o fermento láctico antes e depois de 1857 não é, de modo algum, o mesmo. 
19 Ou melhor, a teoria dos atores-redes busca conjugar os dois modelos, um, bem explícito, sobre a associação, e outro, sub-reptício, sobre a ação. Para esta última funcionar, é preciso uma ontologia adaptada ao princípio de simetria generalizada.

20 "All actual entities share with God this characteristic of self-causation. For this reason every actual entity also shares with God the characteristic of transcending all other actual entities, including God" (A. N. Whitehead, op. cit., p. 223).

21 Sobre a noção de mediação no domínio privilegiado da arte musical, ver o excelente livro de A. Hennion, 1993.
Isto basta para criar história? Não, e sabemos muito bem por quê. A história não pode ser definida por um simples rearranjo de fatores, porque ela não é feita, como uma receita de cozinha, a partir de ingredientes. Por mais heterogêneas, por mais relacionais que sejam as entidades que entrarão em certa combinação, não será por esta razão que daí surgirá a historicidade. O fermento láctico não se compõe de ingredientes esparsos vindos de outras partes, nem mesmo de associações, como na teoria, muito embora radical, dos atores-redes. ${ }^{19}$

Para evitar o tilintar das combinações, o atomismo dos fatores, é preciso, assim, reconhecer em todo composto, em toda concrescência, alguma coisa a mais, alguma capacidade radical e única de inovação. Para isso, é preciso aceitar que os acontecimentos, para merecerem seu nome, sejam em parte sem causa. Por mais absurdo que possa parecer, o realismo exige o abandono da idéia de causalidade como um transporte de forças ou como um deslocamento de formas. A descoberta do fermento em 1857 não se deve nem a Pasteur, que a ela leva seus pressupostos, nem ao laboratório onde se define uma boa prática, nem ao fermento presente desde toda a eternidade e levado à Faculdade de Lille - nem, certamente, a um estilhaçamento de pequenas condições infinitesimais que desafiariam o cálculo mas, no entanto, agiriam, cada uma delas, como uma causa. Para que haja história é preciso que o fermento-de-1857-em-Lille-com-Pasteur seja, em parte, causa sui. ${ }^{20} \mathrm{Em}$ lugar algum do universo pode-se ter o transporte de forças que permita fazer a soma de tal acontecimento a fim de explicar retrospectivamente seu aparecimento. A descoberta-invenção-construção do fermento láctico exige que se lhe dê o estatuto de mediação, quer dizer, de uma ocorrência que não é de todo causa, nem de todo conseqüência, nem completamente um meio, nem completamente um fim. ${ }^{21}$ Pasteur pode ser entendido como um acontecimento do fermento porque é imprevisto, exterior à série de heranças que até então definiam a 'sociedade' do microrganismo, sua trajetória, sua linhagem. Encontrar-se no laboratório para ali ser semeado, cultivado, contado, purificado vai espicaçar o fermento de maneira imprevisível. Correlativamente, a presença durável de um fermento associado a uma fermentação, à atividade química de um ser vivo, constitui, para Pasteur, uma encruzilhada decisiva tanto de sua carreira como de sua pessoa. Quanto aos químicos, ao aceitar Pasteur e seu fermento, tornam-se, numa tradução decisiva, bioquímicos. Nenhum ingrediente, é fácil compreender, entra em tais relações sem nelas se refundir.

Enquanto se fazia da natureza o reino das causas, parecia inverossímil falar de uma historicidade das coisas. A inventividade, 
22 Curiosamente, a passagem de uma visão previsível das causas a uma concepção da ordem pela desordem não modificou esta alternativa, a despeito de I. Prigogine e I. Stengers, 1988. A noção de emergência, que no entanto é muito whiteheadiana, não implica, forçosamente, a historicização simétrica da natureza e da sociedade.

23 Esta historicidade não deve ser confundida com a transformação no tempo das partículas ou dos seres vivos, como nos grandes relatos cosmológicos ou evolucionistas (S. J. Gould, 1991). Invertendo o princípio antrópico, trata-se de fazer os cientistas entrarem na história das coisas. Não apenas contar como os dinossauros desapareceram, mas como os paleontólogos participam da própria história dos dinossauros: duas historicidades complementares, mas distintas. a flexibilidade, a hesitação só podiam vir dos humanos e de sua dolorosa história. Somente eles podiam transcender o reino bruto dos objetos, afirmar sua liberdade contra as restrições viscosas do prático-inerte. Ao ligar os humanos e os não-humanos, o princípio de simetria generalizada escandalizou, já que significava estender a noção de pessoa aos seres da natureza - panpsiquismo, hilozoísmo - ou, ao contrário, mergulhar a invenção do homem no jogo mais ou menos previsível das causas mecanismo, engenharia social. ${ }^{22}$ Como é diferente se todas as entidades transbordarem, transcenderem, ultrapassarem em parte suas causas, suas heranças, seus ascendentes! Os objetos da natureza não oferecem mais, como único modelo ontológico, aquela exigência opiniática, teimosa, obstinada, da substância. Nada mais impede, portanto, de atribuir-lhes um papel na fábrica do mundo humano, sem retornar ao realismo à moda antiga que os historiadores sociais combateram com razão, e sem serem acusados de atribuir aos não-humanos aquela personalidade intencional até agora reservada apenas aos humanos. A natureza partilha com a sociedade a mesma historicidade, sem que, no entanto, o conjunto reunificado se torne imanente ou transcendente, impessoal ou pessoal. A transcendência necessária à inovação se distribui em todos os pequenos descolamentos pelos quais as conseqüências transbordam sua herança. A história das ciências transforma-se, em definitivo, no existencialismo estendido às próprias coisas. Ao tornar-se outra vez histórica, ${ }^{23}$ a natureza torna-se ainda mais interessante, mais realista.

Quanto à vertente da sociedade, ela se transforma ainda mais, e se aproxima do senso comum. Não somos mais prisioneiros perpétuos da linguagem, encerrados nos quadros conceituais, privados para sempre de qualquer acesso às próprias coisas, às quais, como em Kant, só podíamos impor categorias arbitrárias. Nosso espírito, nossa cultura, nossos paradigmas não são simples mós. A despeito de suas hesitações, Pasteur não diz aos fatos como eles devem falar. Mistura-se a eles, partilhando com os fermentos (aos quais ele oferece uma outra oportunidade) sua história, seu corpo, seu laboratório, a assembléia de seus colegas. Ele não só os descobre como os molda. Todos coalescem nesta ocasião, matéria e forma uns dos outros.

Whitehead zomba gentilmente dos filósofos críticos que crêem que nosso espírito está ligado ao mundo apenas pela frágil ponte da percepção, como se uma grande cidade, aberta até então aos ventos do campo que a cerca, pouco a pouco decida se fechar atrás de muralhas, a ponto de só autorizar a passagem por um portão estreito e uma ponte levadiça oscilante. Toda a filosofia do conhecimento provém de tal fragilidade artificialmente man- 
tida, como se o espírito corresse o risco de, a qualquer momento, perder suas preciosas provisões. É preciso demolir as muralhas, autorizar outras passagens, abrir amplamente a cidade para o campo, suprimir as concessões; não faltarão os contatos entre o espírito e o mundo. Não há risco de ruptura nas importações, já que não temos mais, por ascetismo, de nos privar do apelo às coisas da natureza, facilmente acessíveis, transcendentes como nós, históricas como nós, mescladas como nós.

Ao partilhar a transcendência com os objetos e a eles chegar pelos milhares de caminhos da linguagem, da prática, da vida social, não somos mais obrigados a colocar as circunstâncias nem na natureza, nem na sociedade, nem no discurso. Basta colocá-los 'em redes' - mas a palavra já empregada possui agora, graças a Whitehead, a ontologia de suas ambições. Cada ocorrência preenche exatamente, sem nada sobrar ou faltar, seu invólucro espácio-temporal. Não existe ser, como o fermento láctico, ou a gravidade, que 'transborde' de suas condições históricas de emergência, o que não quer dizer, no entanto, que seja resultado apenas do trabalho humano. Não temos mais que escolher entre estas duas versões. Para que a ocorrência se estenda e dê assim a impressão de 'transbordar', é preciso que ocorram outras condições históricas, outros apoios, outros veículos, outras mediações, todos em parte causas de si mesmos.

Só achamos difícil colocar as ontologias em rede porque usamos levianamente os dois pares de advérbios: sempre/nunca, em qualquer lugar/em lugar nenhum. Da emergência do ácido láctico com Pasteur, em 1857, concluímos que 'sempre' esteve lá e que age igualmente 'em qualquer lugar'. Como Pasteur derrubou, em Lille, em 1857, a teoria de Leibig sobre a fermentação por degradação das matérias, concluímos que ela 'nunca' esteve presente, 'em lugar nenhum'. Duplo exagero que congela a história das coisas e obriga a inventar, por contraste, estes relatos de descoberta por cuja crítica comecei este artigo. Já que, embora ignorado até 1857, o fermento sempre existiu, e já que os cientistas são os únicos a se agitar nesta questão, é preciso que Pasteur o tenha descoberto levantando, por virtude própria, o véu que o escondia. Mas Pasteur, seus colegas, os fabricantes de laticínios, os historiadores têm muito o que fazer até estender ao passado a presença retrospectiva do fermento do ácido láctico. Em 1858, 1859, 1860 etc. eles devem proceder a uma 'conclamação' de todos os séculos precedentes, a fim de lhes dar este novo atributo: a presença do fermento recém-descoberto. Os historiadores trabalham como os criadores de programas de computador que substituem, por uma soma módica, a versão 2.1 de um programa pela versão 2.2. É preciso trabalhar tanto no espaço como no 
24 Beneficiei-me, neste artigo, das críticas de Christiane Frémont, tão pertinentes que não pude tirar delas todo o partido que desejaria. tempo para estender a todas as leiterias e queijarias a presença, logo universal, do fermento láctico. É preciso trabalhar ainda mais para esvaziar da história passada a teoria de Liebig e suprimi-la pouco a pouco de todos os manuais - até a 'descoberta' das enzimas, mais tarde nesse mesmo século, e que reformula de novo os fermentos, Pasteur, Liebig e a história retrospectiva da bioquímica. O fermento láctico, ao longo de sua história, jamais exagera nem sua existência nem seu vazio, nem sua localidade nem sua universalidade. Como as outras entidades, ele persevera no ser, mas, em certos lugares, durante um certo tempo, um pouco com a condição de existir em comum com muitas outras que, elas também, não têm acesso nem à substância nem ao vazio, mas que, nas encruzilhadas, 'decidem' sua história. Filamentos, linhagens, trajetórias, heranças, sociedades, rizomas.

Espero haver mostrado, como pretendia, que a metafísica de Whitehead permite dar um passo decisivo na filosofia da história das ciências, bloqueada há algum tempo na questão do papel que convém dar aos não-humanos. Do ponto de vista empírico, igualmente, Whitehead tem bons efeitos, já que permite dar conta de que uma contradição no relato experimental pasteuriano não é verdadeiramente uma contradição, desde que aceitemos abandonar o reino exclusivo das causas. Graças a ele, as redes nas quais a história se divide entre fermentos, cientistas, laboratórios e colegas se tornam mais acessíveis à pesquisa histórica, sem com isso perder seu realismo. Através de um longo desvio pelo kantismo, pelo relativismo radical, pelo princípio da simetria restrita, e em seguida generalizada, retornamos, com a ontologia, ao senso comum, contra o qual, nos aconselhou com algum humor Whitehead, nunca devemos nos chocar. ${ }^{24}$

LATOUR, B.: 'Os objetos têm história? Encontro de Pasteur com Whitehead num banho de ácido láctico'. História, Ciências, Saúde - Manguinbos, II (1), 7-26 mar.-jun. 1995.

Pasteur descobriu, construiu, inventou o ácido lático? Este nó górdio dos estudos sociais das ciências é alegremente cortado quando a cena vivida em 'Lille-1857' se povoa dos personagens conceituais whiteheadianos. A 'natureza' a que se dirige Pasteur não fala a linguagem dos enunciados científicos, mas nem por isso é muda. Ela está saturada de proposições. Na medida em que o personagem de Pasteur é o de um cientista, ele 'é agido' por uma proposição singular, "a tale that perhaps might be told", como diria Whitehead, mas que só se tornará verdadeira ou falsa se Pasteur conseguir fazer corresponder a ela um mundo real capaz de fornecer-lhe seus sujeitos lógicos de um modo que seja prova para "quem quer que julgue com imparcialidade". Híbrido-mediador-tradutor das proposições pastorianas e microrganísmicas, o meio experimental "faz o acontecimento", encontro de onde surgem um novo Pasteur e um novo fermento, parceiros de uma nova história.

PALAVRAS-CHAVE: Pasteur, Whitehead, ácido láctico, historicidade. 


\section{REFERÊNCIAS BIBLIOGRÁFICAS}

Bensaude-Vincent, $\mathrm{B}$.

e Stengers, I. 1992

Bloor, D. 1991

Bloor, D. 1982

Callon M. e Latour, B. 1992

Callon, $\mathrm{M}$. 1986

Canguilhem, G. 1968

Cobb, J. B. 1993

Collins, H., e Yearley, S 1992

Collins, $\mathrm{H}$. 1985

Geison, G. 1974

Gould, S. J. 1991

Hacking, I. 1992

Hennion, A. 1993

Jacq, F.

Jullien, F. 1992

Kuhn, T. 1983

Latour, B. 1993

Latour, B. 1991

Latour, B. 1989

Latour, B. 1984, a

Latour, B. 1984, b
Histoire de la chimie.

Paris, La Découverte.

Knowledge and Social Imagery (second edition with a new foreword). Chicago, University of Chicago Press.

Sociologie de la logique ou les limites de l'épistémologie. Paris, Éditions Pandore.

'Don't Throw the Baby out with the Bath School! A Reply to Collins and Yearley'. Em A.Pickering (org.). Science as Practice and Culture. Chicago, Chicago University Press.

'Éléments pour une sociologie de la traduction. La domestication des coquilles Saint-Jacques et des marins pêcheurs en baie de Saint-Brieue', L'année sociologique, vol. 36, pp. 169-208.

Études d'bistoire et de philosophie des sciences. Paris, Vrin.

'Alfred North Whitehead'. Em D. R. Griffin (org.). Founders of Constructive Postmodern Pbilosophy. Albany, State University of New York Press.

'Epistemological Chicken'. Em A. Pickering (org.). Science as Practice and Culture. Chicago, Chicago University Press.

Changing order. Replication and induction in scientific practice. Londres/Los Angeles, Sage.

'Article Pasteur'. Em C. Gillespie (org.). The Dictionary of Scientific Biography. Nova York, Scribner and Sons.

La vie est belle. Paris, Le Seuil.

'World-making by kind-making: child abuse for example'. Em M. Douglas e D. Hull (orgs.). How classification works. Edimburgo, Edinburgh University Press.

La passion musicale. Une sociologie de la médiation. Paris, A.-M. Métailié.

'La philosophie de l'explication historique en histoire et en histoire des sciences'. Centre de Sociologie da la Innovation (submetido para publicação).

La propension des choses.

Paris, Le Seuil. Col. Travaux.

La structure des révolutions scientifiques.

Paris, Flammarion.

'Pasteur on lactic acid yeast - a partial semiotic analysis', Configurations, I (1), pp. 127-42.

Nous n'avons jamais été modernes. Essai d'anthropologie symétrique. Paris, La Découverte.

La science en action. Paris, La Découverte.

Les Microbes, Guerre et Paix.

Paris, A.-L. Métailié. Col. Pandore.

Irréductions.

Paris, A.-L. Métailié. Col. Pandore. 
BRUNO LATOUR

Licoppe, C.

1994

Pasteur, L.

1939

Prigogine, I., Stengers, I.

1988

Schaffer, S.

1991

Shapin, S., Schaffer, S. 1993

Stengers, I.

1993

Whitehead, A. N. 1978
Éprouver, rapporter et convaincre. Une étude du compte-rendu

expérimental à l'époque moderne. Tese de doutoramento, Paris VII.

Oeuvres complètes.

7 vols., Paris, Masson, tomo VII.

Entre le temps et l'éternité.

Paris, Fayard.

'The Eighteenth Brumaire of Bruno Latour', Studies in History and Pbilosopby of Sciences, XXII.

Le Léviathan et la pompe à air - Hobbes et Boyle entre science et politique. Paris, La Découverte.

L'Invention des sciences modernes.

Paris, La Découverte.

Process and Reality. An Essay in Cosmology.

Nova York, Free Press, p. 79. [1929]

Tradução de Sergio Goes de Paula 